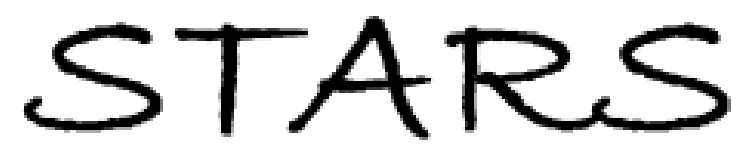

University of Central Florida

STARS

Faculty Bibliography 1990s

Faculty Bibliography

$1-1-1993$

\title{
Efficient Laser Performance Of Ndgdlif4: A New Laser Crystal
}

\author{
X. X. Zhang \\ University of Central Florida \\ M. Bass \\ University of Central Florida
}

A. B. Villaverde

University of Central Florida

J. Lefaucheur

University of Central Florida

A. Pham

University of Central Florida

See next page for additional authors

Find similar works at: https://stars.library.ucf.edu/facultybib1990

University of Central Florida Libraries http://library.ucf.edu

This Article is brought to you for free and open access by the Faculty Bibliography at STARS. It has been accepted for inclusion in Faculty Bibliography 1990s by an authorized administrator of STARS. For more information, please contactSTARS@ucf.edu.

\section{Recommended Citation}

Zhang, X. X.; Bass, M.; Villaverde, A. B.; Lefaucheur, J.; Pham, A.; and Chai, B. H. T., "Efficient Laser

Performance Of Ndgdlif4: A New Laser Crystal" (1993). Faculty Bibliography 1990s. 2930.

https://stars.library.ucf.edu/facultybib1990/2930

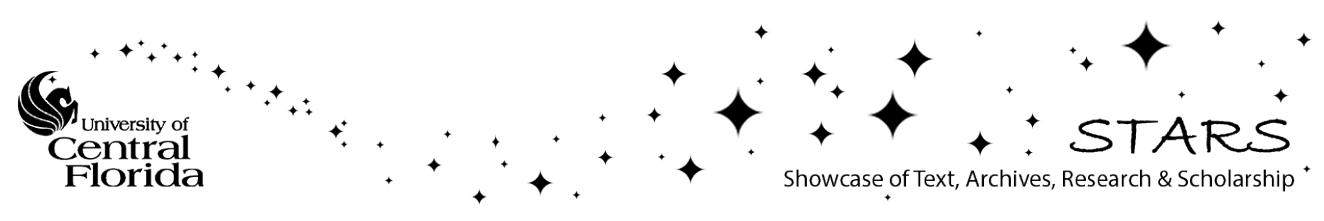




\section{Authors}

X. X. Zhang, M. Bass, A. B. Villaverde, J. Lefaucheur, A. Pham, and B. H. T. Chai 


\section{Efficient laser performance of $\mathrm{Nd}_{\text {:GdLiF }}^{4}$ : A new laser crystal}

Cite as: Appl. Phys. Lett. 62, 1197 (1993); https://doi.org/10.1063/1.108732

Submitted: 02 November 1992 . Accepted: 12 January 1993 . Published Online: 04 June 1998

X. X. Zhang, M. Bass, A. B. Villaverde, J. Lefaucheur, A. Pham, and B. H. T. Chai

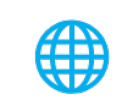

View Online

\section{ARTICLES YOU MAY BE INTERESTED IN}

Spectroscopy and modeling of solid state lanthanide lasers: Application to trivalent $\mathrm{Tm}^{3+}$ and $\mathrm{Ho}^{3+}$ in $\mathrm{YLiF}_{4}$ and $\mathrm{LuLiF}_{4}$

Journal of Applied Physics 95, 3255 (2004); https://doi.org/10.1063/1.1649808

New nonlinear optical crystal: Cesium lithium borate

Applied Physics Letters 67, 1818 (1995); https://doi.org/10.1063/1.115413

Generation of high energy $10 \mathrm{fs}$ pulses by a new pulse compression technique Applied Physics Letters 68, 2793 (1996); https://doi.org/10.1063/1.116609

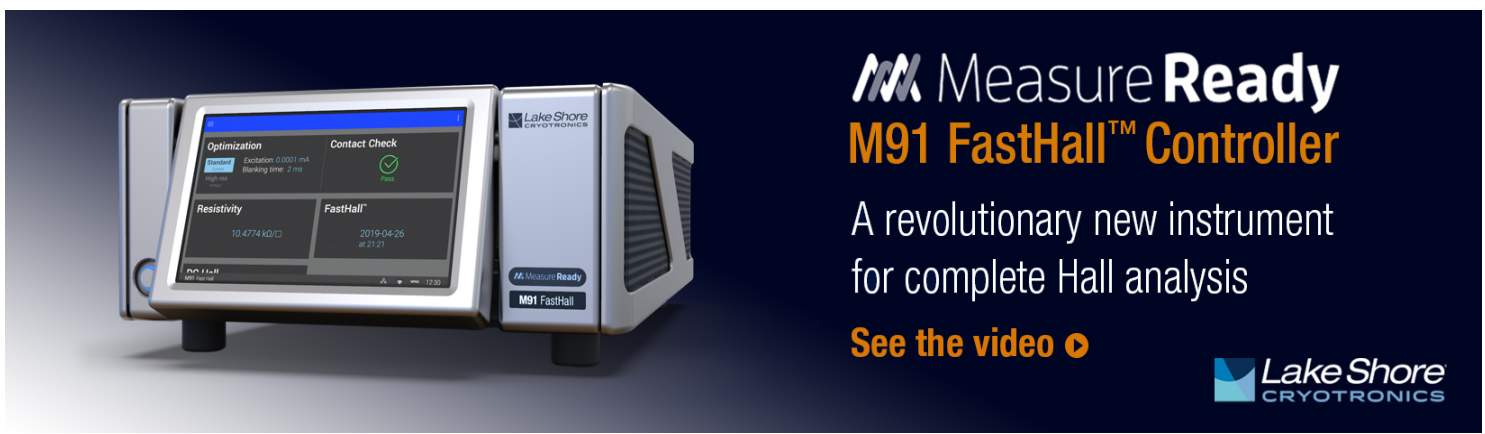




\title{
Efficient laser performance of Nd:GdLiF 4 : A new laser crystal
}

\author{
X. X. Zhang, M. Bass, A. B. Villaverde, ${ }^{\text {a) }}$ J. Lefaucheur, A. Pham, and B. H. T. Chai \\ Center for Research in Electro-optics and Lasers, University of Central Florida, 12424 Research Parkway, \\ Orlando, Florida 32826
}

(Received 2 November 1992; accepted for publication 12 January 1993)

Laser action of $\mathrm{Nd}^{3+}$ doped $\mathrm{GdLiF}_{4}$ (GLF) has been demonstrated for both pulsed and cw laser pumped operation. A slope efficiency of $60 \%$ was obtained in either manner of operation. The spectroscopic properties and laser performance of Nd:GLF are very similar to those of $\mathrm{Nd}$ :YLF. GLF, on the other hand, can be doped with much higher $\mathrm{Nd}^{3+}$ concentration.

We report the efficient lasing performance of a new crystal, $\mathrm{Nd}^{3+}$ doped $\mathrm{GdLiF}_{4}$, which is capable of accepting high $\mathrm{Nd}^{3+}$ concentration. Diode pumped, all solid state, $\mathrm{Nd}^{3+}$ lasers have received major attention recently because of their potentially small size, high efficiency, and long operating lifetime. So far Nd:LiYF 4 (YLF) and $\mathrm{Nd}: \mathrm{Y}_{3} \mathrm{Al}_{5} \mathrm{O}_{12}$ (YAG) are the only commercially available crystals for such applications. Even though YAG and YLF are both good hosts, they can only be doped with a maximum of about 1 at. $\% \mathrm{Nd}^{3+}$ without unacceptable degradation of crystal quality. As a result, the pump light absorption is weak in YAG and YLF lasers and longer samples (about $6 \mathrm{~mm}$ ) are needed for effective diode pumping. Longer samples required more complex focusing optics due to the poor beam quality of diode laser pump light. The result is increased complexity and product cost.

The limitation on the $\mathrm{Nd}^{3+}$ doping concentration in both YLF and YAG results from the size mismatch of the $\mathrm{Nd}^{3+}$ ion and the $\mathrm{Y}^{3+}$ ion in both crystals. The ionic radius of the $\mathrm{Nd}^{3+}$ ion in the eightfold configuration site is $1.12 \AA{ }^{1}$, and that of the $\mathrm{Y}^{3+}$ ion is $1.015 \AA^{\circ}{ }^{1} \mathrm{High} \mathrm{Nd}^{3+}$ doping will cause too much local distortion and degrade the crystal quality. The use of $\mathrm{GdLiF}_{4}$ (GLF) as a host crystal enables doping with higher $\mathrm{Nd}^{3+}$ ion concentration because there is less size mismatch between the dopant ion and the $\mathrm{Gd}^{3+}$ ion (ionic radius $1.06 \AA^{1}$ ) which it replaces.

GLF is isostructural with YLF, as evidenced by the similarities between the spectroscopic properties shown below. Therefore, Nd:GLF is expected to have optical properties similar to those of Nd:YLF such as long fluorescent lifetime and natural birefringence which may be advantageous in certain applications. ${ }^{2,3}$

Single crystals of Nd:GLF were grown by a modified Czochralski pulling technique in our crystal growth facilities. The composition of the melt is LiF: GdF=68:32. An $a$-axis Nd:YLF rod was used as a seed. The pull rate was $0.3 \mathrm{~mm} / \mathrm{h}$ and the rotation rate was $15 \mathrm{rpm}$. Two crystals were grown for the spectroscopic studies and initial laser tests. The $\mathrm{Nd}^{3+}$ doping concentrations in the melt were 5 and 1.3 at. \%, respectively. However, the distribution coefficient of $\mathrm{Nd}^{3+}$ in GLF is estimated to be about 0.8 and so the $\mathrm{Nd}^{3+}$ concentrations in the grown crystals are about 4 and 1 at. \%.

The room temperature absorption spectra of 4 at. \%

a) On leave from Universidade Estadual de Campinas, Campinas, SP, Brazil.
$\mathrm{Nd}^{3+}: \mathrm{GdLiF}_{4}$ and 1.2 at. \% Nd:YLF are given in Fig. 1. The absorption spectra of both samples are almost identical except for the following facts: (1) the absorption coefficient of Nd:GLF is more than three times higher than that of Nd:YLF due, in large part, to the higher Nd concentration in GLF and (2) the existence of the absorption features in the region from 250 to $320 \mathrm{~nm}$ in the Nd:GLF spectra originating from absorption by the $\mathrm{Gd}^{3+}$ ions $\left({ }^{8} S_{7 / 2}\right.$ to $\left.{ }^{6} P_{7 / 2},{ }^{6} I_{7 / 2-17 / 2}\right)$ of the host. The polarized emission spectra in the $1 \mu \mathrm{m}$ region of 1 at. \% Nd:GLF at room temperature are shown in Fig. 2. The main peak is centered at $1.047 \mu \mathrm{m}$ for $\pi$-polarization $(E \| C)$ and at $1.053 \mu \mathrm{m}$ for $\sigma$-polarization ( $E \perp C$ ). The emission spectra are again very similar to that of Nd:YLF. ${ }^{4}$ The fluorescence decay of the ${ }^{4} F_{3 / 2}$ level of $\mathrm{Nd}^{3+}$ in 4 at. $\% \mathrm{Nd}$ :GLF is given by a nonexponential function with a $1 / e$ decay time $\approx 192 \mu \mathrm{s}$, whereas the decay in 1 at. \% Nd:GLF is given by a nearly exponential function with a decay time of $475 \mu$ s. The similarities between the absorption and emission spectra and the fluorescence decay times of Nd:GLF and Nd:YLF indicate that these two crystals are isostructural.

Two samples were cut with flat and parallel faces containing the $c$-axis for laser experiments. They were both AR coated from 1.0 to $1.1 \mu \mathrm{m}$. The crystal lengths, $6 \mathrm{~mm}$ for the 1 at. $\% \mathrm{Nd}$ crystal and $1.8 \mathrm{~mm}$ for the 4 at. \% Nd crystal, were chosen so that the absorbance was about the same in each. The initial laser test employed a concave $(R=5 \mathrm{~cm})$ reflector $(H R$ at $1.0-1.1 \mu \mathrm{m}, H T$ at $790-810$ $\mathrm{nm})$ and a flat partial reflector $(97 \% R$ at $1.0-1.1 \mu \mathrm{m}, H T$

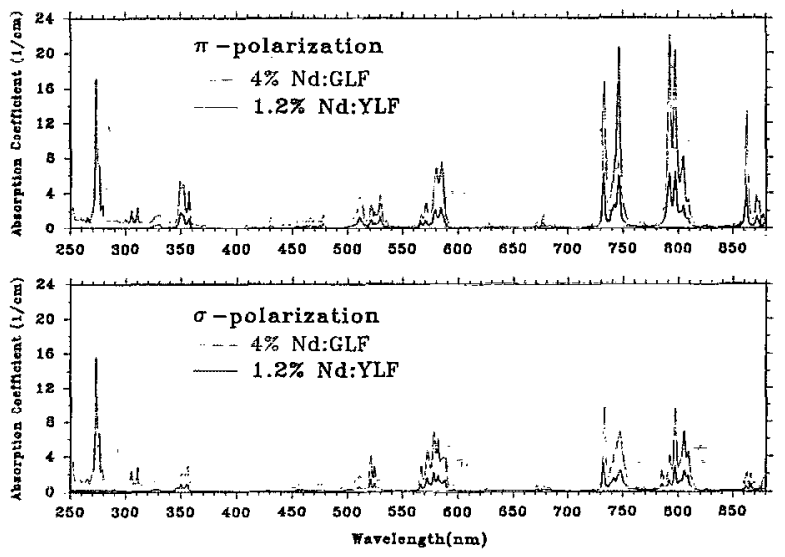

FIG. 1. Polarized absorption spectra of Nd:GdLiF 4 and Nd:LiYF 4 at room temperature. 


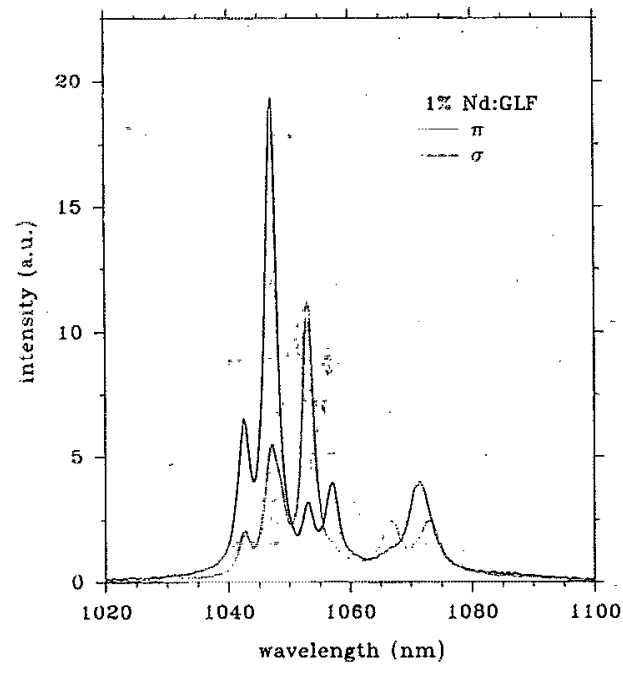

FIG. 2. Polarized emission spectra of 1 at. $\% \mathrm{Nd}^{-\mathrm{GdLiF}_{4}}$ near $1 \mu \mathrm{m}$ at room temperature.

at $790-810 \mathrm{~nm}$ ) to form the laser cavity. Pulsed excitation was achieved with a long pulse Cr:LiSAF laser. $\mathrm{cw}$ excitation employed a Ti:sapphire laser. Both lasers were tuned to $797 \mathrm{~nm}$ to match the absorption peak of the $\mathrm{Nd}^{3+}$ ion in GLF. The spectral band of the Cr:LiSAF laser was about $4 \mathrm{~nm}$, whereas that of the Ti:sapphire was less than $1 \mathrm{~nm}$. As a result, about $75 \%$ of the pump energy was absorbed by the crystals in pulsed operation and about $95 \%$ in $\mathrm{cw}$ operation. The pump light was focused into the $4.5 \mathrm{~cm}$ long laser cavity with a $10 \mathrm{~cm}$ focal length lens and the crystal tested was placed about $4 \mathrm{~mm}$ in front of the flat (output coupler) mirror. For comparison, a commercial $1.2 \%$ Nd:YLF crystal from Lightning Optics, Inc. ( $3 \mathrm{~mm}$ diameter $\times 6 \mathrm{~mm}$ length, also AR coated) was tested in the same resonator using the same pumping conditions.

Lasing from Nd:GLF is linearly polarized along the $c$-axis ( $\pi$-polarization) and occurs at $1.047 \mu \mathrm{m}$, the same wavelength as that of Nd:YLF. The laser output as a function of the absorbed energy or power is given for pulsed operation in Fig. 3(a) and cw operation in Fig. 3(b). The thresholds and the slope efficiencies are summarized in Table I. The thresholds given for pulsed operation are estimated values because they are less than $100 \mu \mathrm{J}$, the least energy our energy meter could detect. These estimates were obtained by measuring the lowest input energy which resulted in lasing and which could be reliably detected with our meter and then inserting neutral density filters to at-
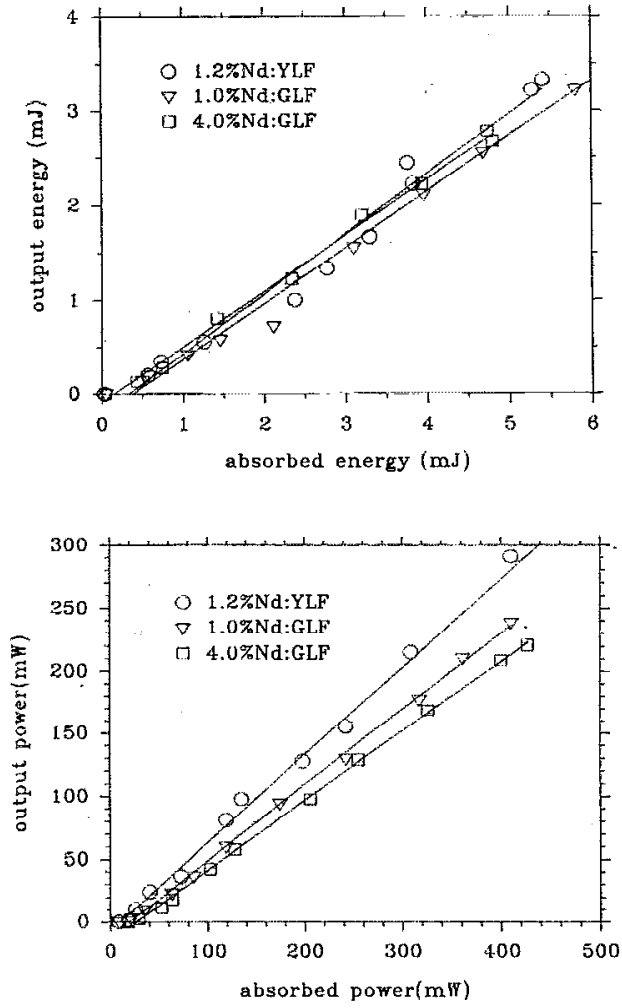

FIG. 3. The laser output as a function of the absorbed energy or power for 1 at. $\% \mathrm{Nd}: \mathrm{GdLiF}_{4}, 4$ at. $\% \mathrm{Nd}: \mathrm{GdLiF}_{4}$ and 1.2 at. \% Nd:LiYF lasers: (a) pulse pumped and (b) cw pumped.

tenuate the pump light in order to reach threshold. The slope efficiency is $60 \%$ in both pulsed and cw operations for 1.0 at. $\% \mathrm{Nd}: \mathrm{GLF}$, compared to $70 \%$ for 1.2 at. $\%$ Nd:YLF. The cw threshold is $10 \mathrm{~mW}$ for 1.0 at. $\%$ Nd:GLF, compared to $9 \mathrm{~mW}$ for 1.2 at: $\%$ Nd:YLF. The slope efficiency of 1.0 at. \% Nd:GLF is lower than that of 1.2 at. \% Nd:YLF, and the threshold slightly higher. We believe that this is due to the higher loss in GLF, since we can see some visual scattering centers in the crystal and we can get a higher slope efficiency and a lower threshold by carefully placing the sample in the cavity. Therefore, the laser performance is expected to improve by improving the optical quality of the crystal. Substantial progress in growing the crystal has been made since the initial trial. The slope efficiencies of the highly doped GLF ( 4 at. \% Nd) are $56 \%$ and $61 \%$ for $\mathrm{cw}$ and pulsed operation, respectively. The difference in the slope efficiencies for the two operations also indicates the imhomogeneity of the crystal.

TABLE I. Comparison of laser performance of Nd:GLF and Nd:YLF.

\begin{tabular}{|c|c|c|c|c|c|c|}
\hline \multirow{2}{*}{$\begin{array}{c}\begin{array}{c}\text { Mode of } \\
\text { operation }\end{array} \\
\text { Crystal }\end{array}$} & \multicolumn{3}{|c|}{ Pulsed } & \multicolumn{3}{|c|}{$\mathrm{cw}$} \\
\hline & $\begin{array}{l}1.2 \text { at. } \% \\
\text { Nd:YLF }\end{array}$ & $\begin{array}{l}1.0 \text { at. } \% \\
\text { Nd:GLF }\end{array}$ & $\begin{array}{l}4.0 \text { at. } \% \\
\text { Nd:GLF }\end{array}$ & $\begin{array}{l}1.2 \text { at. } \% \\
\text { Nd:YLF }\end{array}$ & $\begin{array}{l}1.0 \text { at. } \% \\
\text { Nd:GLF }\end{array}$ & $\begin{array}{l}4.0 \text { at. } \% \\
\text { Nd:GLF }\end{array}$ \\
\hline $\begin{array}{l}\text { Threshold } \\
\text { Slope }\end{array}$ & $30 \mu \mathrm{J}^{\mathrm{a}}$ & $50 \mu \mathrm{J}^{\mathrm{a}}$ & $40 \mu \mathrm{J}^{\mathbf{a}}$ & $9 \mathrm{~mW}$ & $10 \mathrm{~mW}$ & $18 \mathrm{~mW}$ \\
\hline $\begin{array}{c}\text { efficiency } \\
(\%)\end{array}$ & 70 & 60 & 61 & 70 & 60 & 56 \\
\hline
\end{tabular}

${ }^{\text {a}}$ Estimated values, see text for explanation. 
It is not surprising that the threshold of highly doped GLF is about twice that of low concentration YLF and GLF for $\mathrm{cw}$ operation. The threshold of a cw laser is inversely proportional to the product of the fluorescent decay time and the emission cross section assuming otherwise identical conditions. Since the decay time of 4 at. $\%$ Nd:GLF $(192 \mu \mathrm{s})$ is only about half of that of low concentration YLF $(442 \mu \mathrm{s})$ and GLF $(\approx 475 \mu \mathrm{s})$ we can account for the measured threshold difference. Comparing the fluorescent decay time and the laser threshold of GLF to YLF and considering the relatively high loss in GLF, enables one to conclude that the cross section of $\mathrm{Nd}$ doped GLF is at least equal to or larger than that of YLF. Making the same comparison between the high and low concentration Nd doped GLF one can see that the cross section is not affected by the concentration.

In summary, we have identified a new laser host,
$\mathrm{Nd}: \mathrm{GdLiF}_{4}$, and demonstrated low threshold, high efficiency laser action with both pulsed and cw pumping. We have shown that the spectroscopic and laser properties of Nd:GLF are very similar to those of Nd:YLF. However, $\mathrm{Nd}$ :GLF offers the possibility of accommodating many more $\mathrm{Nd}^{3+}$ dopant ions.

The authors would like to thank Dr. P. LiKamWa and Dr. A. Miller for the use of their Ti:sapphire laser and Lightning Optical Co. for providing the Nd:YLF crystal used in the comparison study.

'D. R. Lide, Ed., CRC Handbook of Chemistry and Physics, 71st ed. (CRC, Boca Raton, Ann Arbor, Boston, 1990), pp. 4-126.

${ }^{2}$ T. M. Pollak, W. F. Wing, R. J. Grasso, E. P. Chicklis, and H. P. Jenssen, IEEE J. QE-18, 159 (1982).

${ }^{3}$ J. E. Murray, IEEE J. Quantum Electron. QE-19, 488 (1983).

${ }^{4}$ A. L. Harmer, A. Linz, and D. R. Gabbe, J. Phys. Chem. Solids 30, 1483 (1969). 